\title{
Acetylator Status Among Newly Diagnosed and Recurrent Tuberculosis Patients from Kupang, Eastern Part of Indonesia
}

\author{
Edhyana Sahiratmadja' \\ Ika Agus Rini ${ }^{2}$ \\ Simeon Penggoam ${ }^{3}$ \\ Afandi Charles ${ }^{2}$ \\ Ani Melani Maskoen ${ }^{1,2}$ \\ Ida Parwati ${ }^{4}$ \\ 'Division of Biochemistry and Molecular \\ Biology, Department of Biomedical \\ Sciences, Faculty of Medicine, Universitas \\ Padjadjaran, Bandung, Indonesia; ${ }^{2}$ Health \\ Research Unit, Faculty of Medicine, \\ Universitas Padjadjaran, Bandung, \\ Indonesia; 'aboratorium Mikrobiologi, \\ RSUD Prof. Dr. WZ Johannes, Kupang, \\ Indonesia; ${ }^{4}$ Department of Clinical \\ Pathology, Faculty of Medicine, \\ Universitas Padjadjaran, Bandung, \\ Indonesia
}

Correspondence: Edhyana Sahiratmadja Division of Biochemistry and Molecular Biology, Department of Biomedical

Sciences, Faculty of Medicine, Universitas Padjadjaran, Jl. Raya Bandung - Sumedang KM 2I, Jatinangor, Sumedang, Jawa Barat, 45363, Indonesia

Tel +62 227795594

Fax +62 227795595

Email e.sahiratmadja@unpad.ac.id
Purpose: N-acetyltransferase- 2 enzyme in the liver, encoded by NAT2 gene, plays a central role in metabolizing tuberculosis (TB) drug isoniazid (INH). Low compliance of patients toward six-month TB therapy and internal host factors, ie comorbid diseases, immune status, and genetic profiles, are factors leading to treatment failure and recurrence of pulmonary TB infection. This study aimed to explore the NAT2 acetylator status among newly diagnosed and recurrent pulmonary TB patients in eastern part of Indonesia.

Patients and Methods: Archived DNA of TB patients $(n=124)$ and healthy controls $(\mathrm{n}=124)$ were sequenced, and NAT2 acetylator status was determined, then categorized as fast, intermediate, or slow acetylators. Pulmonary TB patients who had no previous TB treatment history were designated as newly diagnosed pulmonary $\mathrm{TB}$, whereas patients with a history of TB treatment were designated as recurrent pulmonary TB. The demographic, clinical, and microbiological data between pulmonary TB groups were compared, and acetylator status was described among groups.

Results: Male was more significantly prevalent in the recurrent pulmonary TB group $(\mathrm{p}=0.025)$, and anemia was more prevalent in new pulmonary TB $(\mathrm{p}=0.003)$. The acetylator status in pulmonary TB patients compared to healthy controls were rapid (33.9\% vs $48.1 \%$ ), intermediate $(57.8 \%$ vs $33.0 \%)$, and slow acetylators $(8.3 \%$ vs $18.9 \%)$, respectively. Interestingly, the rapid and intermediate acetylator were significantly more prevalent in pulmonary TB patients than in healthy controls $(\mathrm{p}=0.023, \mathrm{OR}=2.58 \quad(1.12-5.97)$. Furthermore, no differences were found in acetylator status between new and recurrent pulmonary $(\mathrm{p}=0.776)$.

Conclusion: Rapid and intermediate acetylators status predominated the pulmonary TB patients in Kupang, eastern part of Indonesia, postulating different genetic makeup in this area. As the pulmonary TB patients in Kupang exhibit more rapid acetylator phenotype, the acetylator status might be relevant to be checked before TB therapy for adjusting treatment dose to prevent drug resistances.

Keywords: acetylator status, NAT2, Indonesia, tuberculosis, recurrence

\section{Introduction}

Pulmonary tuberculosis (TB) has been known for centuries as one of the deadliest diseases due to a single infection agent, Mycobacterium tuberculosis. Around 10 million people have been infected with $\mathrm{TB}$ and there were 1.2 million deaths related to TB globally in 2018, of which most cases occur in developing countries, including Indonesia. The estimated incidence rate per year in Indonesia is placed third globally. ${ }^{1}$ Four-drugs regimen, including rifampicin, isoniazid, 
pyrazinamide, and ethambutol, has been used for around 40 years to treat pulmonary $\mathrm{TB}$, yet recurrence and death numbers due to this disease are still burdening. ${ }^{2}$ Low compliance of patients toward six-month chemotherapy and internal host factors, ie comorbid diseases, immune status, and genetic profiles, become factors leading to treatment failure and pulmonary TB recurrence. ${ }^{3}$ Based on pharmacogenetics variation, recently, host-genetic profiles have emerged as a promising intervention in determining the success of treatment for pulmonary TB patients. $^{4}$

One of the genes that play essential roles in TB drug pharmacokinetics is NAT2 gene, encoding N-acetyltransferase-2 enzyme in the liver. ${ }^{4,5}$ This enzyme metabolizes INH into less active forms by acetylating the drug molecules, thus determining how much active drug concentration in the plasma. ${ }^{4,5}$ Previous studies showed three phenotypic host acetylator statuses were observed due to various polymorphisms in the NAT2 gene: rapid, intermediate, and slow acetylators. ${ }^{4}$ Slow acetylator phenotype is associated with adverse drug responses such as nausea, drug-induced liver injury, peripheral neuropathy, and sideroblastic anemia which may lead to discontinuation of treatment. ${ }^{6,7}$ On the other hand, rapid acetylator phenotype could enhance drug metabolism in the liver, leading to the lower concentration of INH in the plasma below the requirement to kill the bacteria, thus causing treatment failure and the emergence of resistance. ${ }^{8}$ Therefore, pharmacogenetic profiling of NAT2 gene becomes essential to achieve successful treatment.

As Indonesia accounts for many TB patients globally, the pharmacogenetic profiling of NAT2 gene is of great interest. There is a high proportion of TB patients in this archipelagic country. Studies in Western and Central Indonesia have been reported recently, resulting in predominantly intermediate acetylators in this area. ${ }^{9,10}$ Interestingly, NAT2 gene profile in other populations in the eastern part of Indonesia has not been explored. East Nusa Tenggara is a rural province in eastern Indonesia. This area has an estimated TB incidence of around 18,000 in 2019, with compliance percentage of treatment among patients just around $66 \%{ }^{11}$ Socioeconomic factors may contribute to patient compliance in these populations. However, pharmacogenetic profiles may also affect antiTB drug therapy's success and the rate of TB recurrence. ${ }^{12}$ Therefore, this study aimed to explore $N A T 2$ acetylator status gene among newly diagnosed and recurrent pulmonary TB patients in eastern part of Indonesia.

\section{Materials and Methods \\ Study Design}

This study was a descriptive and analytical study, with a retrospective design including pulmonary TB patients (newly diagnosed pulmonary $\mathrm{TB}$ patients and patients with recurrent $\mathrm{TB}$ ) and healthy controls from the neighborhood. This study was part of a study exploring the susceptibility genes among TB patients from Kupang at the island of Timor, located in a remote area in the eastern part of Indonesia. Informed consent about the susceptibility genes study was obtained from all subjects, and DNA was stored for various genetic studies, including this study. Our study was conducted in accordance with Declaration of Helsinki and the study protocol was approved by the Ethical Committee of Faculty of Medicine Universitas Padjadjaran Bandung under no. 136/UN6.C2.1.2/KEPK/ PN/2012.

In brief, archived DNA of TB patients $(n=124)$ recruited in 2011 at Prof W. Z. Johannes General Hospital, Kupang, were used. Healthy controls $(n=124)$ were also recruited to explore the NAT2 acetylator status in the general population. Pulmonary TB patients were diagnosed according to standard hospital procedure as directed in WHO guideline, ie history taking of signs and symptoms of TB infection, physical examinations, chest radiology examinations, and positive result of three-time points of sputum examination. Mycobacterial culture was examined in a part of patients, of which drug susceptibility test and Mycobacterium tuberculosis spoligotyping test were performed as described previously. ${ }^{13}$

Pulmonary TB patients who had no previous TB treatment history were designated as newly diagnosed pulmonary TB, whereas patients with a history of TB treatment were designated as recurrent pulmonary TB. Patients with HIV seropositive or fasting glucose serum of $>200 \mathrm{mg} / \mathrm{dL}$ were excluded from this study.

\section{DNA Extraction and NAT2 Gene Sequencing}

Venous blood from pulmonary TB patients and healthy controls were collected in $3 \mathrm{~mL}$ EDTA tubes, then stored in $4^{\circ} \mathrm{C}$ before sending to Bandung, West Java, about 4 hours flight from Kupang. In brief, DNA was isolated from blood according to the manufacturer's protocol (QIAamp 
DNA Blood Mini Kit, Cat no. 51104, Qiagen). The amplification of NAT2 gene and the sequencing process was performed based on our study protocol published previously. ${ }^{14}$

\section{Acetylator Status Assessment}

The determination of acetylator status was conducted using seven single nucleotide polymorphisms in NAT2 gene, ie rs 1801279 for $191 \mathrm{G}>\mathrm{A}$, rs 1041983 for $282 \mathrm{C}>\mathrm{T}$, rs 1801280 for $341 \mathrm{~T}>\mathrm{C}$, rs1799929 for $481 \mathrm{C}>\mathrm{T}$, rs1799930 for $590 \mathrm{G}>\mathrm{A}$, rs 1208 for $803 \mathrm{~A}>\mathrm{G}$, and rs 1799931 for $857 \mathrm{G}>\mathrm{A}$. Sequence data analyses were performed using Bioedit software (version 7.2.5.0) and nucleotide BLAST (Genebank reff. KR231610). The NAT2 genotype identification was performed by analyzing 7 SNPs of NAT2 according to the Arylamine N-acetyltransferase Gene Nomenclature website (http://nat.mbg.duth.gr/Human\%20NAT2\%20alleles_2013. $\mathrm{htm})$. The nucleotide changes at $\mathrm{rs} 1801280 \quad(341 \mathrm{~T}>\mathrm{C})$, rs1799930 (590G $>A)$, and rs1799931 (857G $>A)$ were designated as NAT2 $* 5$, NAT2 $* 6$, NAT2 $* 7$, respectively. The subjects were then categorized as fast, intermediate, or slow acetylator phenotype.

\section{Statistical Analyses}

Data statistics were performed in Microsoft Excel 365 (Microsoft Corp., Redmond, WA, USA). The demographic, clinical, and microbiological data were compared between newly diagnosed and recurrent TB groups, then analysis was performed using Mann-U Whitney tests (for numerical data) and chi-square test (for categorical data), and p-value $<0.05$ was designated as significant. To determine whether the SNPs genotypes in NAT2 were in Hardy-Weinberg equilibrium (HWE), Chi-square tests were conducted and $p$ value $\geq 0.05$ indicated that the SNPs genotype were in equilibrium. The NAT2 haplotype status were presented in numbers (n). The acetylator status frequencies in different groups (newly diagnosed TB, recurrent TB, and healthy controls) were compared using Pearson Chi-square or Fischer's exact test as appropriate, then odds ratio (OR) with $95 \%$ confidence intervals $(95 \% \mathrm{CI})$ were also calculated.

\section{Results}

\section{Demographic, Clinical, and Microbiological Profile of Pulmonary TB Patients}

Our study in Kupang recruited initially 124 participants pulmonary TB, consisting of $99(79.8 \%)$ new and 25
(20.2\%) recurrent pulmonary TB patients. However, patients were excluded $(n=9)$ due to HIV seropositivity $(\mathrm{n}=1)$, high serum glucose suspected for Diabetes Mellitus $(n=6 ; 4.8 \%)$ and incomplete data $(n=2)$. The characteristic data of both group pulmonary TB patients is shown in Table 1.

When comparing new and recurrent pulmonary TB patients, there was a significant difference in gender. Male was more prevalent in the recurrent pulmonary TB group ( $p=0.025)$. Furthermore, no significant differences in age, erythrocyte sediments rate, and body mass index between both groups. Interestingly, hemoglobin concentration in newly diagnosed pulmonary TB was significantly lower compared to recurrent TB (median $10.9 \mathrm{mg} / \mathrm{dL}$ vs $12.1 \mathrm{mg} / \mathrm{dL} ; \mathrm{p}=0.018$ ), of which anemia was more prevalent in new pulmonary TB $(\mathrm{p}=0.003)$.

In a subset of the patients, drug sensitivity tests were performed, showing that the number of samples resistant to all drugs seemed to be higher in group of recurrent TB. Specifically, INH resistance cases were documented higher in recurrent TB than newly-diagnosed TB patients. Furthermore, spoligotyping detection showed that nonBeijing strain of M.tuberculosis predominated infection in this population, both in newly diagnosed and recurrent TB groups. Since the test was only performed in a limited number of patients, no statistical analyses were conducted, and data is only presented in frequency (Table 1).

\section{NAT2 Polymorphisms and Acetylator Status of Pulmonary Tuberculosis Patients}

The distribution of SNPs in seven rs contributed to NAT2 gene variations among pulmonary TB patients from Kupang, Nusa Tenggara Timur, Indonesia is described in Table 2. Four polymorphisms that change the amino acid sequences $(\mathrm{rs} 1801280, \mathrm{p}=0.616 ; \mathrm{rs} 1799930, \mathrm{p}=0.286 ; \mathrm{rs} 1208, \mathrm{p}=$ 0.653; and rs1799931, $\mathrm{p}=0.332$ ) were in Hardy-Weinberg equilibrium. Based on those polymorphisms, there were 18 genotypes found in this population, and classified based on their inferred phenotype as rapid $(\mathrm{n}=37 ; 33.9 \%)$, intermediate $(\mathrm{n}=63 ; 57.8 \%)$, and slow acetylators $(\mathrm{n}=9 ; 8.3 \%)$. For comparison, the frequencies of acetylator status in healthy controls were $48.1 \%, 33.0 \%$, and $18.9 \%$ for rapid, intermediate, and slow phenotype, respectively. The most common alleles found in this study were NAT2 $* 4$ (wild type; rapid phenotype), NAT2*6A, NAT2*6B, and NAT2*7A. There was "unknown" variation detected in this study, which had not been documented in NAT2 gene bank; that was 
Table I Clinical Characteristic of Patients with Newly Diagnosed and Recurrent Pulmonary Tuberculosis from Kupang, Nusa Tenggara Timur, Eastern Part of Indonesia

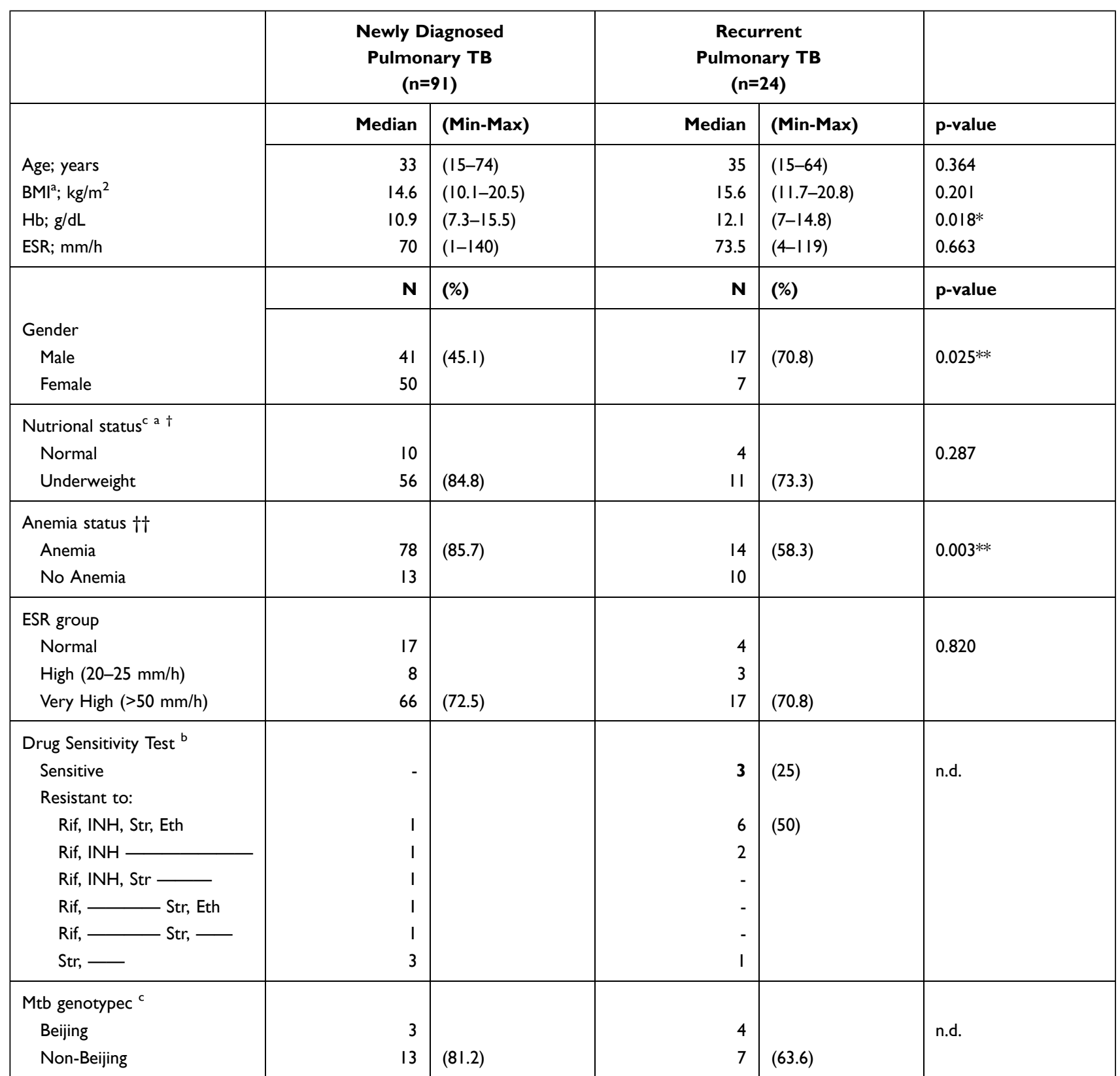

Notes: Data retrieved from ${ }^{\mathrm{a}} 8 \mathrm{I}$ patients; ${ }^{\mathrm{b}} 20$ patients, ${ }^{\mathrm{c}} 27$ patients. $\dagger$ Nutritional Status according to BMI for normal I8-22 and underweight $<18$. $\dagger \dagger$ Anemia designated as WHO guideline for men $<13 \mathrm{~mm} / \mathrm{dL}$ and women $<12 \mathrm{~mm} / \mathrm{dL}$. Statistical analyses $\mathrm{p}<0.05$ designated as significant for *non-parametric compared median and $* *$ chi-square Abbreviations: BMI, body mass index; Hb, hemoglobin; ESR, erythrocyte sediment rate; TB, tuberculosis; Rif, Rifampicin; INH, isoniazid; Str, Streptomycin; Eth, Ethambutol; n.d, not determined; Mtb, Mycobacterium tuberculosis.

a combination of $282 \mathrm{C}>\mathrm{T} \quad(\mathrm{rs} 1041983), 590 \mathrm{G}>\mathrm{A}$ (rs1799930), $625 \mathrm{C}>\mathrm{T}$ that inferred as slow phenotype due to homozygous recessive state. A new polymorphism 625 $\mathrm{C}>\mathrm{T}$ had not been described elsewhere in NAT2 gene database. However, since it was a non-sense mutation and did not change the amino acid sequence, this polymorphism might not change the function of NAT2 enzyme.
Interestingly, the rapid and intermediate acetylator were significantly more prevalent in pulmonary TB cases than in healthy controls $(\mathrm{p}=0.023$, OR $=2.58(1.12-$ 5.97)). However, comparing the frequency of acetylator status among newly diagnosed and recurrent pulmonary TB resulted in no significant difference between both groups $(\mathrm{p}=0.776)$, as shown in Table 3 . 
Table 2 Distribution of Single Nucleotide Polymorphisms Contributed to NAT2 Gene Variations Among Pulmonary Tuberculosis Patients from Kupang, Nusa Tenggara Timur, Eastern Part of Indonesia

\begin{tabular}{|c|c|c|c|c|c|c|c|c|c|c|}
\hline & & & rs 1801279 & rsI04I983 & rs I $80 \mid 280$ & rsI799929 & rsI799930 & & rs 1208 & rs179993 I \\
\hline \multirow[t]{3}{*}{ Genotypes } & Inferred & $\mathbf{n}$ & $191 \mathrm{G}>\mathrm{A}$ & $282 C>T$ & $34 \mid \mathrm{T}>\mathrm{C}$ & $48 \mid C>T$ & $590 \mathrm{G}>A$ & $625 \mathrm{C}>\mathrm{T}$ & $803 A>G$ & $857 \mathrm{G}>\mathrm{A}$ \\
\hline & Phenotypes & & R64Q & Y94Y & III4T & LI6IL & R197Q & L209L & K268R & G286E \\
\hline & & & & & NAT 2*5 & & NAT $2 * 6$ & & NAT $2 * 12$ & NAT 2*7 \\
\hline NAT $2 * 4 / 4$ & Rapid (WT) & 35 & GG & CC & TT & CC & GG & & AA & GG \\
\hline NAT $2 * 4 / 12$ A & Rapid & 1 & & & & & & & AG & \\
\hline NAT $2 * 4 / 12 M$ & Rapid & 1 & & CT & & CT & & & AG & \\
\hline NAT $2 * 4 / 5 B$ & Intermediate & 4 & & & TC & CT & & & AG & \\
\hline NAT $2 * 4 / 5 \mathrm{C}$ & Intermediate & 1 & & & TC & CT & & & AG & \\
\hline NAT $2 * 4 / 5 \mathrm{E}$ & Intermediate & 1 & & & TC & & GA & & AG & \\
\hline NAT2*4/5Q & Intermediate & 1 & & & TC & & GA & & & \\
\hline NAT2*4/5S & Intermediate & 1 & & & TC & & & & & GA \\
\hline NAT2*4/5U & Intermediate & 1 & & CT & TC & CT & GA & & AG & \\
\hline NAT2 $* 4 / 6$ A & Intermediate & 4 & & CT & & & GA & & & \\
\hline NAT $2 * 4 / 6 \mathrm{~B}$ & Intermediate & 15 & & & & & GA & & & \\
\hline NAT2 $* 4 / 6 \mathrm{~J}$ & Intermediate & 13 & & $\mathrm{CT} / \mathrm{TT}$ & & & GA & & & GA \\
\hline NAT $2 * 4 / 7$ A & Intermediate & 18 & & & & & & & & GA \\
\hline NAT2*4/7B & Intermediate & 3 & & TT & & & & & & GA \\
\hline NAT $2 * 6 \mathrm{~A} / 6 \mathrm{~A}$ & Slow & 6 & & TT & & & AA & & & \\
\hline NAT2*7B/7B & Slow & 2 & & TT & & & & & & AA \\
\hline Unknown $†$ & Intermediate & 1 & & & TC & CT & GA & & & \\
\hline Unknown $\dagger$ & Slow & 1 & & TT & & & AA & CT & & \\
\hline
\end{tabular}

Notes: $\uparrow$ Unknown is designated as variations that are not registered according to the data base of Arylamine $\mathrm{N}$-acetyltransferase (NATs) for Human NAT2 Alleles (haplotypes) http://nat.mbg.duth.gr/Human\%20NAT2\%20alleles_2013.htm. Intermediate acetylator when the alleles are heterozygous; slow acetylators when the alleles are in homozygote recessive variant.

Abbreviations: NAT2, N-acetyltransferase 2; WT, wild type.

Table 3 Distribution of Acetylator Status in Newly Diagnosed and Recurrent Pulmonary Tuberculosis Compared to Healthy Controls from Kupang, Nusa Tenggara Timur, Eastern Part of Indonesia

\begin{tabular}{|l|c|c|c|c|c|}
\hline \multirow{2}{*}{ Group } & \multicolumn{3}{|c|}{ Acetylator Status, n (\%) } & \multirow{2}{*}{ P value* } & \multirow{2}{*}{ OR (95\% CI) } \\
\cline { 2 - 4 } & Rapid & Intermediate & Slow & & \\
\hline Healthy Controls & $5 I(48.1)$ & $35(33.0)$ & $20(18.9)$ & $0.023^{\text {a }}$ & $2.58(1.12-5.97)$ \\
Pulmonary TB patients & $37(33.9)$ & $63(57.8)$ & $9(8.3)$ & & \\
Newly diagnosed & $28(32.2)$ & $52(59.8)$ & $7(8.0)$ & $0.776^{\text {b }}$ & n.a. \\
Recurrent & $9(40.9)$ & II (50.0) & $2(9.1)$ & & \\
\hline
\end{tabular}

Notes: *rapid and intermediate vs slow acetylator status (chi-square test), ${ }^{a}$ Control vs pulmonary TB patients, ${ }^{b}$ Newly diagnosed vs recurrent pulmonary TB patients. Abbreviations: $\mathrm{TB}$, tuberculosis; $\mathrm{OR}$, odds ratio; $\mathrm{Cl}$, confidence interval; n.a, not available.

\section{Discussion}

Recurrent pulmonary TB infection worldwide is reported in around $13 \%$ of all TB cases. Our study has detected that around $20 \%$ of cases are recurrent pulmonary TB, higher than estimated global data in $2017 .{ }^{15}$ The recurrent TB proportion varies significantly in different areas; for example, in Iran, Zambia, and South Africa, the recurrent TB proportions are $8.3 \%, 15.3 \%$, and $26 \%$, respectively. ${ }^{16-18}$ Recurrent pulmonary TB could be caused by either reactivation of M.tuberculosis from previous infection or re- infected from exogenous sources. ${ }^{19}$ In this study, recurrent pulmonary $\mathrm{TB}$ is significantly higher in male patients, confirming that males become one of the risk factors contributing to recurrent cases. ${ }^{20,21}$ Other risk factors associated with recurrent TB cases include smoking, poor treatment adherence, uncontrolled HIV-comorbid infection, and specific clinical pictures such as residual cavitation, more significant area of involved lung tissue, and positive sputum culture at two months of first treatment. ${ }^{3}$ Previous studies have shown associations between TB 
recurrence and drug resistance. ${ }^{22,23}$ Our study has revealed more MDR cases, as defined by simultaneous rifampicin and isoniazid resistance, documented in recurrent TB cases despite a small number of tests. These findings suggest the importance of using rapid methods to detect drugresistance M.tuberculosis to determine which regimens should be used in recurrent pulmonary TB cases.

Genotype diversity of NAT2 gene has been known to affect TB therapy response. Different genotypes can influence how rapidly NAT2 enzyme metabolizes INH drugs in the liver. Different ethnicities have shown different proportions of rapid, intermediate, and slow phenotypes. The frequency of slow acetylators varies in different countries, for example, in Latvia (51.8\%), Senegal (49\%), and Brazil $(41 \%),{ }^{24-26}$ which is much higher than in our study population. Interestingly, several Asian countries reported slow acetylator phenotypes in lower frequencies, for example, China (15.2\%) and South Korea (14.4\%). ${ }^{27,28}$ Moreover, studies in western and central Indonesia have shown the frequencies of slow acetylators are around 36\% in pulmonary TB patients with Javanese-Sundanese ethnicity. Of note, healthy Malay-Indonesian accounts for 38\%, similar to healthy Buginese (42\%). ${ }^{9,10,29}$ Interestingly, our study in Kupang, East Nusa Tenggara revealed that only around $8 \%$ of pulmonary TB patients were slow acetylator phenotypes. Predomination of rapid-intermediate acetylator in TB patients in Kupang, suggesting that different genetic background of this population may affect the NAT2 gene polymorphism diversity. Based on historical perspective, Kupang people residing in Timor Island, East Nusa Tenggara, have mixed origin from Austronesian and Polynesian ancestry. ${ }^{30,31}$ This hypothesis should be explored in other parts of East Nusa Tenggara and other areas in eastern Indonesia such as Maluku and West Papua.

Both slow and rapid acetylation could influence the drug response in TB patients regarding of the INH metabolism speed in the liver. Slow acetylators are associated with increased INH levels in plasma and hepatotoxicity observed in TB patients, confirming the study conducted in Javanese and Sundanese TB patients. ${ }^{9}$ The NAT2*6A allele is reported as an ultra-slow acetylator that can be used to determine the effects of NAT2's genetic polymorphism on metabolism and drug toxicity. ${ }^{32}$ On the other hand, a substantial percentage of rapid acetylators in this population should raise other awareness since a meta-analysis study showed that rapid acetylators contribute to microbiological failure, acquired drug resistance, and TB relapse. ${ }^{8}$ The rapid acetylator individuals could exhibit lower INH levels as presented in bloodstream. This is due to INH molecules that is rapidly acetylated, thus decreasing INH exposure to MTB in the affected tissues. ${ }^{33}$ Molecular docking study of mutated MT-K268R model (polymorphsms at $803 \mathrm{~A}>\mathrm{G}$ in $N A T 2 * 4, N A T 2 * 12$ and $N A T 2 * 13$ ) has shown less binding affinity toward INH and increase acetyl-INH score, leading to more INH acetylation. ${ }^{34}$ As we noted that INH drug resistance was found in this population (especially in people with recurrent pulmonary TB), further study with larger participants might be needed to confirm the association of rapid acetylator phenotypes and recurrent TB cases and drug resistance in Kupang population.

Our study has several limitations among others that the study was not designed to detect adverse effects such as hepatotoxicity and treatment failure, especially due to the nature of the study site which is in a remote area and laboratory examinations are scarce. Further study needs to be designed considering the role of pharmacogenetic background of individuals living in area with possible different genetic makeup across the islands of Indonesia. The study on population genetic profile is of great interest. Furthermore, the sample size is not calculated accordingly as we had included total respondents who were willing to participate in the study period. Moreover, some of the clinical information and other data are sometimes lacking. Therefore, it is imperative to register the complete information in the medical record or registry that would strengthen the results of the TB treatment with first-line drugs in Indonesia.

\section{Conclusion}

The slow acetylator status in pulmonary TB in Kupang population in our study was $8.3 \%$, much lower than previous study conducted in other parts of Indonesia, suggesting different genetic background in eastern part of Indonesia. There was no difference in acetylator status between newly and recurrent pulmonary TB. As majority of pulmonary TB patients in Kupang are rapid and intermediate acetylator status, these might influence the emergence of drug resistance and recurrence. The acetylator status might be relevant as the rationalization in recurrent TB patients to be checked prior to INH therapy to adjust treatment dose to prevent further antimicrobial resistance for successful TB treatment. 


\section{Acknowledgments}

The authors thank all the general practitioners and nurses for examining the patients in Prof W. Z. Johannes General Hospital, Kupang. We also thank the patients, families and their neighbors for participating in this study.

\section{Disclosure}

The authors declare that they have no conflicts of interest for this work. This study was financially supported by the Ministry of Research and Technology, Republic of Indonesia. The content of this paper is solely the responsibility of the authors and does not necessarily represent the official views of the funders.

\section{References}

1. World Health Organization. Global Tuberculosis Report 2019. Geneva: World Health Organization; 2019.

2. Chakraborty S, Rhee KY. Tuberculosis Drug Development: history and Evolution of the Mechanism-Based Paradigm. Cold Spring Harb Perspect Med. 2015;5(8):a021147. doi:10.1101/cshperspect.a021147

3. Comstock GW, Golub JE, Panjabi R. Recurrent tuberculosis and its risk factors: adequately treated patients are still at high risk. Int J Tuberc Lung Dis. 2007;11(8):828-837.

4. Ramachandran G, Swaminathan S. Role of pharmacogenomics in the treatment of tuberculosis: a review. Pharmgenomics Pers Med. 2012;5:89-98. doi:10.2147/PGPM.S15454

5. Das RP, Majumder M, Roy B. Pharmacogenomics of anti-TB drugs-related hepatotoxicity. Pharmacogenomics. 2008;9 (3):311-321. doi:10.2217/14622416.9.3.311

6. Werely CJ, Donald PR, van Helden PD. NAT2 polymorphisms and their influence on the pharmacology and toxicity of isoniazid in TB patients. Per Med. 2007;4(2):123-131. doi:10.2217/174105 41.4.2.123

7. Wang P, Pradhan K, Zhong X-B, Ma X. Isoniazid metabolism and hepatotoxicity. Acta Pharm Sin B. 2016;6(5):384-392. doi:10.1016/j. apsb.2016.07.014

8. Pasipanodya JG, Srivastava S, Gumbo T. Meta-analysis of clinical studies supports the pharmacokinetic variability hypothesis for acquired drug resistance and failure of antituberculosis therapy. Clin Infect Dis. 2012;55(2):169-177. doi:10.1093/cid/cis353

9. Yuliwulandari R, Prayuni K, Susilowati RW, et al. NAT2 slow acetylator is associated with anti-tuberculosis drug-induced liver injury severity in Indonesian population. Pharmacogenomics. 2019;20 (18):1303-1310. doi:10.2217/pgs-2019-0131

10. Yuliwulandari R, Susilowati RW, Razari I, Viyati K, Umniyati H, Prayuni K. N-acetyltransferase 2 polymorphism and acetylation profiles in Buginese ethnics of Indonesia. Ann Hum Genet. 2019;83 (6):465-471. doi:10.1111/ahg.12341

11. Kementerian Kesehatan Republik Indonesia. Evaluasi Program Tuberkulosis 2018 Dan Upaya Menuju Eliminasi Tuberkulosis 2030. Jakarta: Kementerian Kesehatan Republik Indonesia; 2019.

12. Millet JP, Orcau À, De Olalla PG, Casals M, Rius C, Caylà JA. Tuberculosis recurrence and its associated risk factors among successfully treated patients. $J$ Epidemiol Community Health. 2009;63 (10):799-804. doi:10.1136/jech.2008.077560

13. Parwati I, van Crevel R, Sudiro M, et al. Mycobacterium tuberculosis population structures differ significantly on two Indonesian Islands. J Clin Microbiol. 2008;46(11):3639-3645. doi:10.1128/ JCM.00605-08
14. Sahiratmadja E, Penggoam S, Maskoen AM, et al. Distribution of rs1801279 and rs1799930 polymorphisms in NAT2 gene among population in Kupang, Nusa Tenggara Timur, Indonesia. Indones Biomed J. 2018;10(1):56-61. doi:10.18585/inabj.v10i1.330

15. World Health Organization. Global Tuberculosis Report 2018. Geneva: World Health Organization; 2018.

16. Moosazadeh M, Bahrampour A, Nasehi M, Khanjani N. The incidence of recurrence of tuberculosis and its related factors in smear-positive pulmonary tuberculosis patients in Iran: a retrospective cohort study. Lung India. 2015;32(6):557-560. doi:10.4103/0970-2113.168113

17. Mutembo S, Mutanga JN, Musokotwane K, et al. Urban-rural disparities in treatment outcomes among recurrent TB cases in Southern Province, Zambia. BMC Infect Dis. 2019;19(1):1-8. doi:10.1186/ s12879-019-4709-5

18. Hermans SM, Zinyakatira N, Caldwell J, Cobelens FGJ, Boulle A, Wood R. High Rates of Recurrent Tuberculosis Disease: a Population-level Cohort Study. Clin Infect Dis. 2020;3-10.

19. Zong Z, Huo F, Shi J, et al. Relapse versus reinfection of recurrent tuberculosis patients in a national tuberculosis specialized hospital in Beijing, China. Front Microbiol. 2018;9(8):1-8. doi:10.3389/ fmicb.2018.01858

20. Korhonen V, Soini H, Vasankari T, Ollgren J, Smit PW, Ruutu P. Recurrent tuberculosis in Finland 1995-2013: a clinical and epidemiological cohort study. BMC Infect Dis. 2017;17(1):721. doi:10.1186/s12879-017-2818-6

21. Dooley KE, Lahlou O, Ghali I, et al. Risk factors for tuberculosis treatment failure, default, or relapse and outcomes of retreatment in Morocco. BMC Public Health. 2011;11(1):140. doi:10.1186/14712458-11-140

22. Sun Y, Harley D, Vally H, Sleigh A. Impact of multidrug resistance on tuberculosis recurrence and long-term outcome in China. PLoS One. 2017;12(1):1-11.

23. Bestrashniy JRBM, Nguyen VN, Nguyen TL, et al. Recurrence of tuberculosis among patients following treatment completion in eight provinces of Vietnam: a nested case-control study. Int J Infect Dis. 2018;74:31-37. doi:10.1016/j.ijid.2018.06.013

24. Igumnova V, Capligina V, Krams A, et al. Genotype and allele frequencies of isoniazid-metabolizing enzymes NAT2 and GSTM1 in Latvian tuberculosis patients. J Infect Chemother. 2016;22 (7):472-477. doi:10.1016/j.jiac.2016.04.003

25. Toure A, Cabral M, Niang A, et al. Prevention of isoniazid toxicity by NAT2 genotyping in Senegalese tuberculosis patients. Toxicol Reports. 2016;3:826-831. doi:10.1016/j.toxrep.2016.10.004

26. Forestiero FJ, Cecon L, Hirata MH, et al. Relationship of NAT2, CYP2E1 and GSTM1/GSTT1 polymorphisms with mild elevation of liver enzymes in Brazilian individuals under anti-tuberculosis drug therapy. Clin Chim Acta. 2013;415:215-219. doi:10.1016/j.cca.2012.10.030

27. Cho HJ, Koh WJ, Ryu YJ, et al. Genetic polymorphisms of NAT2 and CYP2E1 associated with antituberculosis drug-induced hepatotoxicity in Korean patients with pulmonary tuberculosis. Tuberculosis. 2007;87(6):551-556. doi:10.1016/j.tube.2007.05.012

28. Chen B, Li JH, Xu YM, Wang J, Cao XM. The influence of NAT2 genotypes on the plasma concentration of isoniazid and acetylisoniazid in Chinese pulmonary tuberculosis patients. Clin Chim Acta. 2006;365(1):104-108. doi:10.1016/j.cca.2005.08.012

29. Susilowati RW, Prayuni K, Razari I, Bahri S, Yuliwulandari R. High frequency of NAT2 slow acetylator alleles in the Malay population of Indonesia: an awareness to the anti-tuberculosis drug induced liver injury and cancer. Med J Indones. 2017;26(1):7-13. doi:10.13181/mji.v26i1.1563

30. Mona S, Grunz KE, Brauer S, et al. Genetic admixture history of Eastern Indonesia as revealed by Y-chromosome and mitochondrial DNA analysis. Mol Biol Evol. 2009;26(8):1865-1877. doi:10.1093/molbev/msp097

31. Gomes SM, Bodner M, Souto L, et al. Human settlement history between Sunda and Sahul: a focus on East Timor (Timor-Leste) and the Pleistocenic mtDNA diversity. BMC Genomics. 2015;16(1):70. doi:10.1186/s12864-014-1201-x 
32. Selinski S, Blaszkewicz M, Getzmann S, Golka K. N-Acetyltransferase 2: ultra-slow acetylators enter the stage. Arch Toxicol. 2015;89(12):2445-2447. doi:10.1007/s00204-015-1650-2

33. Unissa AN, Subbian S, Hanna LE, Selvakumar N. Overview on mechanisms of isoniazid action and resistance in Mycobacterium tuberculosis. Infect Genet Evol. 2016;45:474-492. doi:10.1016/j. meegid.2016.09.004
34. Unissa AN, Sukumar S, Hanna LE. The Role of N-Acetyl Transferases on Isoniazid Resistance from Mycobacterium tuberculosis and Human: an In Silico Approach. Tuberc Respir Dis (Seoul). 2017;80(3):255-264. doi:10.4046/trd.2017.80.3.255

\section{Publish your work in this journal}

Pharmacogenomics and Personalized Medicine is an international, peer-reviewed, open access journal characterizing the influence of genotype on pharmacology leading to the development of personalized treatment programs and individualized drug selection for improved safety, efficacy and sustainability. This journal is indexed on the American Chemical Society's Chemical Abstracts Service (CAS). The manuscript management system is completely online and includes a very quick and fair peer-review system, which is all easy to use. Visit http://www.dovepress.com/testimonials.php to read real quotes from published authors. 